\title{
Alguns aspectos da leitura no Brasil: comportamentos antigos, alternativas possíveis
}

\author{
Adauto Locatelli Taufer" \\ Fabiano Tadeu Grazioli**
}

\section{Resumo}

O presente trabalho parte de uma análise de alguns dados dos últimos resultados do Programa de Avaliação Internacional dos Alunos (PISA) e do Retratos da Leitura no Brasil (RLB), o primeiro disponibilizado pelo INEP, o segundo pelo Instituto Pró-Livro, na qual se discutem os baixos índices de leitura numa perspectiva que problematiza o perfil do leitor nacional e os equívocos relacionados ao percurso de sua formação quando se procura delineá-lo a partir do espaço escolar, justamente por este espaço se apresentar fragilizado, distante de investimentos de diversas naturezas que, de fato garantam visualizar o perfil do qual tanto se lastima. $\mathrm{O}$ intuito não é revelar uma realidade já conhecida para constranger docentes e discentes, mas retomá-la, já que os índices, a nosso ver apontam mais uma vez para ela, e colocá-la em diálogo com os estudos de José Hélder Pinheiro Alves (2013), Antonio Candido (1995), Silvia Castrillón (2011), Graça Paulino e Rildo Cosson (2009), Tzvetan Todorov (2020), Regina Zilberman (2009), entre outros, para sugerir algumas reflexões. No final, apresentamos alternativas possíveis no contexto da educação básica brasileira, como a criação de comunidades interpretativas, aproveitando as orientações de Annie Rouxel (2013), em sintonia com o que propõe Cecilia Bajour (2012) acerca da escuta como prática de leitura, metodologias que, se bem observadas, recuperam aspectos que estão na natureza da recepção do texto literário, o que, por si só, já é uma sugestão.

Palavras-chave: Leitura literária; Literatura na escola; Práticas de leitura.

* Docente na Universidade Federal do Rio Grande do Sul (UFRGS). Realizou estágio pós-doutoral em Teoria Literária e Escrita Criativa no Programa de Pós-Graduação em Letras da Pontifícia Universidade Católica do Rio Grande do Sul (PUCRS). Doutor e mestre em Letras com ênfase na Literatura Brasileira, Luso-Africana e Portuguesa (UFRGS). Professor de Literatura e Língua Portuguesa do Colégio de Aplicação da UFRGS. Atua principalmente nos seguintes temas: educação literária, escrita criativa; formação docente, formação do leitor, mediação de leitura e produção textual. É líder do grupo de pesquisa - Grupo de Investigação sobre Práticas de Língua Portuguesa e Literatura na Educação Básica - cadastrado no CNPq. Tem publicações e organizações de obras voltadas à escrita criativa, à mediação de leitura e à formação do leitor literário. E-mail: adautotaufer@gmail.com

** Docente da Universidade Regional Integrada do Alto Uruguai e das Missões (URI). Doutor e mestre em Letras pelo Programa de Pós-Graduação em Letras da Universidade de Passo Fundo (UPF). Professor do Departamento de Linguística, Letras e Artes da URI, Campus de Erechim/RS. E-mail: tadeugraz@yahoo. com.br

Data de submissão: ago. 2021 - Data de aceite: out. 2021 http://dx.doi.org/10.5335/rdes.v17i3.12575 


\section{Introdução}

Oh! bendito o que semeia Livros... livros à mão cheia... E manda o povo pensar! O livro caindo n'alma É gérmen - que faz a palma, É chuva - que faz o mar. (ALVES, 1986, p. 77, grifo nosso)

Há muito se discute sobre aspectos atinentes à leitura no Brasil. E, de fato, se considerarmos, pelos menos, dados do Programa de Avaliação Internacional dos Alunos (PISA) e do Retratos da Leitura no Brasil (RLB), constataremos que os indicadores dos percentuais de leitura e de leitores são alarmantes. Antes de discutirmos a respeito desses dados, é importante esclarecermos que, de maneira bastante abrangente, o tamanho amostral analisado por esses dois indicadores de leitura passam pelo crivo do que consideram ser práticas de leitura e de escrita ideais. Não vamos aqui tecer considerações a respeito da escrita, pois o foco da nossa reflexão é a leitura. Por fim, registramos que esses dados, um expressivo recorte, não refletem a realidade que possa ser estendida a todas as iniciativas de fomento à leitura no território nacional.

Considerando o discurso do lugar-comum a respeito do solo poroso sobre o qual a leitura se alicerça, habitamos, sim, um país em que pouco se lê e em que se escreve mal, precariamente, em decorrência desse déficit de leitura. Graças a informações há bastante tempo sedimentadas no senso comum, damo-nos conta de que se escreve mal aqui não só pela falta de leitura, mas também pela minguada prática de escrita. Sabemos, porém, que o hábito de "escrever mal", muitas vezes, se dá porque as expectativas de quem "lê bem" são frustradas, pois o produtor textual não se portou exatamente como o leitor textual esperava. Aliás, os dados do PISA $^{1}$ e do RLB ${ }^{2}$ são bastante claros a respeito das fragilidades presentes nos hábitos de leitura dos brasileiros. Como já dito por Monteiro Lobato (1882-1948), "Quem mal lê, mal ouve, mal fala, mal vê", uma vez que, para Lobato, "Uma nação é feita de homens e livros". Temos pleno acordo com essas duas premissas do criador da personagem Dona Benta a avó amorosa e sábia de Narizinho e de Pedrinho, que ama os livros e os lê para seus netos - embora tenhamos bastante clareza a respeito do contexto em que a segunda delas foi proferida. ${ }^{3}$

Voltando à discussão a respeito da "precariedade" de leitores no Brasil, os dados relativos à crise da leitura sinalizam "uma crise na escola em decorrência da parceria historicamente estabelecida entre o ensino e a aquisição das habilidades de ler e de escrever" (ZILBERMAN, 2009, p. 28). Para Zilberman, em "A esco- 
la e a leitura da literatura", há equívocos de interpretação a respeito da participação da escola nos aspectos concernentes ao ensino de leitura, ${ }^{4}$ considerando que, em muitas instituições da educação básica, os processos relativos ao ato de ler são realizados mecanicamente, entretanto, para a autora, quando atua de maneira eficiente, a escola:

dota as crianças do instrumental necessário e automatiza seu uso, por meio de exercícios que ocupam o primeiro - mas dificilmente o segundo - ano do ensino fundamental. Ler coincide então com a aquisição de um hábito e tem como consequência o acesso a um patamar do qual dificilmente se regride, a não ser quando falta competência à introdução do aluno à escrita. Porém, a ação implícita no verbo em causa não torna nítido seu objeto direto; ler, mas ler o quê? Dessa maneira, o sentido da leitura nem sempre se esclarece para o aluno que é beneficiário dela. Por conseguinte, mesmo aprendendo a ler e conservando essa habilidade, a criança não se converte necessariamente em um leitor, já que este se define, em princípio, pela assiduidade a uma entidade determinada - a literatura. (ZILBERMAN, 2009, p. 30 - grifo nosso).

De acordo com Zilbeman, portanto, tornar-se leitor vai muito além da decodificação de palavras, pois, na sua visão, se denomina leitor aquele que mantém o contato permanente com a leitura, com a literatura. Ainda, de acordo com o pensamento dessa autora, para que a escola não restrinja à leitura à mera decodificação vocábulos - distanciando, portanto, o estudante da leitura e, consequentemente, não o habilitando a ser leitor - é capital que o professor entenda ser a leitura um "procedimento de apropriação da realidade, bem como o sentido do objeto por meio do qual ela se concretiza: a obra literária" (Ibidem, p. 30). Dessa maneira, o entendimento, por parte do professor, de que as estratégias adotadas à valorização da leitura devam recuperar o contato do estudante com o texto literário, é fundamental para que as práticas de leitura, com vistas à consolidação da formação do leitor, ocorram: o contato permanente entre $o$ leitor e o texto.

Entendemos que esse contato, entretanto, deva se distanciar de "finalidades precípuas" ou de "cobranças ulteriores" (ZILBERMAN, 2009, p. 36) no que tange às atividades de leitura, pois a experiência de leitura personalizada, que abarque o estímulo à imaginação e à descoberta particular de cada leitor, não pode ser substituída pela interpretação única e exclusiva do professor acerca do texto literário, uma prática hierárquica e limitadora sobre a qual ainda, infelizmente, se alicerçam muitas bases do ensino de leitura na educação básica e, igualmente, em muitas instituições de ensino superior. Neste, muitas vezes, privilegiando e legitimando análises de textos literários apoiados exclusivamente no discurso dos docentes que ministram as disciplinas e na consagrada fortuna crítica a respeito dos autores e de suas obras, por vezes, unicamente 
canônicas; naquela, reduzindo o olhar sobre o texto literário fragmentado no recorte do livro didático ou na visão de mão única do professor.

Assim, com o propósito de tornar o estudante também um protagonista nas atividades que envolvam a leitura, aliviando os ombros já há muito sobrecarregados do professor, "é preciso ouvir a experiência do outro não como menor, ou menos universal, mas diferente" (ALVES, 2013, p. 36), tornando as atividades de leitura momentos profícuos de compartilhamento de experiências e de possibilidades concretas de interlocução entre estudantes e professores numa via de mão dupla.

Depois desse breve preâmbulo, no presente artigo, pretendemos discutir algumas causas dos baixos índices de leitura no Brasil, considerando o levantamento realizado pelo PISA e pelo RLB, além de problematizarmos a participação da escola na constituição de sujeitos leitores. Esclarecemos que nosso objetivo não é o de promover nenhuma "caça às bruxas", tampouco relegar ao professor a responsabilidade de algumas "falhas" do sistema educacional, pois temos plena convicção de que as "fraturas expostas", que atinem às práticas de leitura e à formação de leitores, não dependem apenas dos docentes, mas, fundamentalmente, de um programa consistente do Governo Federal que, de verdade, se ocupe e se preocupe com a qualidade do ensino brasileiro, elaborando projetos educacionais voltados: (a) à formação continuada dos professores, garantindo-lhes programas permanentes para atualização e capacitação profissionais; (b) à melhoria infraestrutural de boa parte das instituições educacionais, sobretudo às instituições públicas há tempo abandonadas e sucateadas; (c) à redução das desigualdades entre os ensinos público e privado, garantido, verdadeiramente, educação de qualidade a todos os estudantes do território nacional; (d) à remuneração digna e justa aos profissionais da Educação, dando-lhes segurança financeira para sustentarem dignamente suas famílias e para investirem em suas formações, vinculando-se a cursos de pós-graduação, por exemplo, e não os obrigando a trabalharem três turnos por dia, de segunda-feira a sexta-feira, com o propósito de obterem salários satisfatórios ao atendimento de suas necessidades básicas; enfim, (e) a um programa de governo preocupado com e sensível às "feridas abertas" há muitas décadas no ensino brasileiro, principalmente no que se relaciona às muitas chagas expostas a respeito da leitura.

A seguir, nas próximas seções, apresentamos alguns dados do PISA e do RLB que, segundo o olhar desses dois indicadores, deflagram uma realidade bastante preocupante a respeito do perfil do leitor nacional. Além disso, discutiremos a importância de garantir o direito à leitura como uma necessidade fundamental 
do ser humano. Por fim, defenderemos a prática da escuta no compartilhamento das impressões de leitura como uma alternativa que permita serem ouvidas as vozes dos leitores dentro de uma comunidade interpretativa de leitura.

\section{A crise da leitura e o direito de ler}

\section{[...], a crise da leitura é igualmente uma} crise da escola, e vice-versa. Cabe, pois, compreender as histórias respectivas e concomitantes da instituição ligada ao ensino e à aquisição da prática da leitura, para apontar o papel que a escola pode vir a desempenhar, se tiver como meta a superação das dificuldades experimentadas nos dois campos, ação de que talvez ambos se beneficiem.

(ZILBERMAN, 2009, p. 19, grifo nosso)

Ao nos debruçarmos sobre os dados do mais recente Programa de Avaliação Internacional dos Alunos (PISA-2018), verificamos que, no Brasil, o salto qualitativo - correspondente à leitura de que necessitamos para alcançar a média atingida por países como Coreia, Canadá e Finlândia, nações que ocupam, respectivamente, as três primeiras posições no ranking do PISA - ainda está longe de ser dado. A título de exemplificação, traçamos um breve comparativo dos dados brasileiros desse programa entre os anos de 2015 e 2018. Por meio da análise dos dados gerados, observamos que o Brasil obteve, em 2018, seu melhor desempenho em letramento em leitura, alcançando a marca de 413 pontos, apenas 3 pontos a mais em relação à edição de 2015. Embora tenha havido uma sensível melhora no campo da leitura, sabemos que essa tímida diferença entre o penúltimo e o último ranking do PISA pouco ou quase nada eleva o Brasil a níveis satisfatórios acerca da competência leitora. Essa estatística, na verdade, deixa-nos, no mínimo, "congelados". Evidentemente, não sejamos ingênuos ao estabelecermos a comparação desses dados entre o Brasil e esses outros três países que ocupam as principais posições nessa pole position da leitura, considerando um importante conjunto de fatores, imbricados entre si, e dos quais ainda estamos muito distantes para atingir a meta de leitura almejada, quais sejam: investimento maciço na estrutura do sistema educacional, propostas claras e consistentes de formação docente, postura discente comprometida com o estudo, entre outros. Sem nos esquecermos de mencionar a superioridade do PIB desses países em relação ao brasileiro, dado que reflete, sobremaneira, sobre os recursos destinados, anualmente, à Educação.

$\mathrm{Na}$ Coreia, por exemplo, país em cuja cultura a valorização do ensino está solidificada no imaginário e nas ações de sua população, o investimento maciço em Educação é uma realidade inconteste: os professores têm plano de carreira robus- 
to, pois recebem remuneração alta e são, pois, valorizados, ocupando uma posição de admiração e de prestígio na sociedade, que atribui respeito e importância ao trabalho docente. Se é verdade que o governo coreano se ocupa em qualificar seus professores antes de eles iniciarem o trabalho em sala de aula, também é verdade que há preocupação contínua direcionada à melhoria da estrutura e do funcionamento das instituições educacionais. $\mathrm{E}$ esse é, verdadeiramente, o resultado da importância atribuída pela população coreana à Educação, grafada, de fato, com letra maiúscula. Infelizmente, dessa realidade ainda estamos muito distanciados cultural, espacial e temporalmente, pois sabemos que, contrastando com a Coreia, a educação (aqui redigida com letra minúscula), no Brasil, não é tida como um valor, como uma prioridade, como um bem cultural para a maioria dos habitantes. Afinal, para boa parte da nossa população e, sobretudo, para muitos governantes, que, há anos, décadas e séculos, mantêm os olhos muito bem fechados para o sistema educacional brasileiro, a atividade laboral exercida pelos professores é irrelevante e pouco importante; amesquinhada, portanto. Ademais, a postura (ou a falta dela) evidenciada por muitos dos nossos estudantes corrobora a posição defendida por uma parcela bastante expressiva dos brasileiros: o desprezo pelo sistema de ensino. Enquanto na Coreia, novamente aqui adotada como exemplo de país que possui uma realidade muito contrastante à nossa, os estudantes e suas famílias veem no estudo oportunidades vitais de ascensão social e de sobrevivência, aqui, o corpo docente enfrenta desafios localizados em patamares menos elevados para que a sala de aula seja um ambiente propício à aprendizagem.

Ainda de acordo com dados do PISA, $41 \%$ dos estudantes brasileiros relataram a dificuldade que os professores enfrentam diariamente para iniciar as aulas, considerando o longo tempo desprendido na tentativa de acalmar os estudantes e de obter o silêncio necessário. Esse percentual difere bastante da média evidenciada pela Organização para Cooperação e Desenvolvimento Econômico (OCDE): 26\%. Só por esse percentual brasileiro distanciado do da OCDE, percebemos o quanto caminhamos a passos lentos rumo a um ambiente adequado à aprendizagem em sala de aula, tendo em vista o tempo gasto para o início das atividades laborais do professor, sem contar com as inúmeras intervenções que ele tem de fazer diariamente, ao longo da aula, para conseguir pôr em prática parte de seu planejamento já bastante prejudicado pelas condições inadequadas de trabalho. Qual o saldo desse descaso de boa parte dos estudantes para com o sistema educacional? Quem perde e quem ganha como esse tipo de atitude?

Perdem, primeiramente, os discentes que, há muito tempo, passam de uma série 
a outra da etapa escolar com lacunas de aprendizagem que, talvez, nunca serão preenchidas; perdem, sequencialmente, os docentes que, frustrados, seguem, muitas vezes, sem qualquer sucesso, tentando ressignificar suas práticas e suas escolhas metodológicas sem, entretanto, nenhum apoio da sociedade; perdem as famílias que veem seus filhos evadirem a educação básica e ingressarem no mercado de trabalho, realizando atividades laborais sub-remuneradas que os deixarão estagnados, sem qualquer possibilidade de ascensão intelectual, profissional, social; perdem, por fim, a sociedade menos letrada como um todo porque continuará a se constituir como massa de manobra, servindo ad eternum a uma minoria detentora do poder econômico e, principalmente, do poder político num país feito o Brasil, em cujas bases de sua estruturação encontram-se desigualdades sociais, acentuadas pelas discrepâncias existentes entre a má distribuição de renda - pois "quanto mais cresce a riqueza, mais aumenta a péssima distribuição de bens" (CANDIDO, 1995, p. 235) - e a falta de equidade entre os ensinos público e privado, são latentes e potencializadas e perpetuadas há décadas; ganham, todavia, essa mesma minoria que detém o poder político e o capital econômico, relegando aos que não tiveram a oportunidade de ter acesso ao ensino de qualidade, sobretudo o público, qualquer possibilidade de escalada e de mobilidade social.
Continuando a discussão a respeito das estatísticas a respeito da leitura no Brasil, é importante registrarmos alguns contundentes resultados obtidos por meio da investigação realizada pelo Instituto Pró-Livro a respeito dos Retratos da Leitura no Brasil de 2019. Na mesma esteira do que apresentamos em relação resultados do PISA-2018, os dados do RLB-2019 são significativamente preocupantes, pois caminham ao encontro do que já foi postulado há bastante tempo por Drummond (1902-1987), “A leitura é uma fonte inesgotável de prazer, mas, por incrível que pareça, a quase totalidade não sente esta sede".

De acordo com os dados gerados para a $5^{\text {a }}$ edição da pesquisa acerca do RLB2019, a pouca atenção atribuída à leitura é muito evidenciada entre os brasileiros, considerando os percentuais deveras preocupante e bastante desanimadores a seguir registrados:

- entre os anos de 2015 e 2019, houve uma significativa redução do percentual de leitores, passando $56 \%$ para $52 \%$. Embora pareça pouco representativa uma queda de apenas $4 \%$, se considerarmos os dados do senso comum a respeito do pouco contato dos brasileiros com a leitura, essa pequena queda representa uma significativa derrota para quem diariamente fomenta o hábito de leitura; 
- entre os brasileiros acima de 5 anos que não leram nenhum livro nos três meses anteriores à realização da pesquisa ${ }^{6}, 48 \%$ da população brasileira está inserida nesse grupo, ou seja, algo em torno de 93 milhões de brasileiros. Esse dado conflagra um importante sinal de alerta, considerando que quase metade da população pertencente à faixa etária descrita não leu nenhum livro;

- entre o percentual de brasileiros que deixou de ler, os $82 \%$ de leitores registrados na pesquisa de 2015 caiu para $68 \%$ em 2019 . O dado estarrecedor é que são leitores que possuem ensino superior, contrariando a ideia sedimentada no imaginário popular de que quem não lê, lê muito pouco ou quase nada lê está inserido entre o grupo de leitores que possuem escolaridade precária;

- entre o percentual de brasileiros que deixou de ler, estão os pertencentes às classes mais economicamente privilegiadas da sociedade brasileira. O percentual de leitores baixou de 76\% (2015) para $67 \%$ (2019). O problema evidenciado aqui, portanto, não contempla dificuldades financeiras, tampouco dificuldades de acesso para aquisição de livros, dado que é ainda mais preocupante.
Por fim, é crucial fazermos o registro de que, ainda segundo os dados da pesquisa do RLB-2019, nosso país, entre os anos de 2015 e 2019, obteve uma expressiva queda de 4,6 milhões de leitores, um dado nada animador para uma nação que possui um número de habitantes bastante expressivo de não-leitores, que leem mal e, consequentemente, pouco contribuem à constituição da massa crítica tão cara à aproximação do Brasil às realidades de países como a Coreia, entre outras nações que investem pesadamente na formação de leitores. Entretanto, ainda que os dados apresentados sejam desmotivadores, essa pesquisa apontou que, embora de maneira muito rudimentar, o brasileiro, em média, lê em torno de cinco livros ao ano: metade desse número constitui-se em leituras parciais das obras e à outra metade é reservada a leitura integral dos livros. Entre os títulos mais acessados, a Bíblia Sagrada eclode como a obra mais lida.

Tanto os dados apresentados pela pesquisa do PISA-2018 quanto os elencados pela pesquisa do RLB-2019, como se pôde perceber, apontam que ainda há muito a ser feito para elevar o Brasil ao patamar de uma nação que reconhece ser a leitura um valor capital, uma prioridade educacional. Mesmo que esses dados sejam frustrantes, nós, que trabalhamos diariamente com o propósito de formar leitores, não podemos negar aos leitores e aos não-leitores o direito à literatura a que todos têm, temos. 
Candido (1995) no importante e sempre atual ensaio intitulado "O direito à literatura", quando o autor aproxima 0 direito de ler aos direitos humanos (saúde, roupas, moradia, estudo, e alimentação) apresentando um breve panorama histórico a respeito da mudança de discurso da elite brasileira, incluindo aí o discurso da classe política, em relação aos menos privilegiados economicamente, aos desvalidos - postula que "a alimentação, a moradia, o vestuário, a instrução, a saúde, a liberdade individual, o amparo da justiça pública, a resistência à opressão etc." (CANDIDO, 1995, p. 241) são direitos indispensáveis a todos os seres humanos; entretanto, "o direito à crença, à opinião, ao lazer e, por que não, à arte e à literatura" (Ibidem, p. 241) também deve ser assegurado a todos os cidadãos, independente do estrato social a que pertençam e da condição financeira que possuem, pois, para Candido, "não há povo e não há homem que possa viver sem" a literatura (CANDIDO, 1995, p. 242). Além de esse direito básico não poder ser negado a nenhum ser humano, para Candido a literatura pode e deve se constituir em um direito inalienável de todo o ser humano porque, nas palavras do autor, primeiramente

[...] a literatura corresponde a uma necessidade universal que deve ser satisfeita sob pena de mutilar a personalidade, porque pelo fato de dar forma aos sentimentos e à visão de mundo ela nos organiza, nos liberta do caos e portanto nos humaniza. Negar a fruição da literatura é mutilar a nossa humanidade. (CANDIDO, 1995, p. 256).
E sequencialmente:

[...] a literatura pode ser um instrumento consciente de desmascaramento, pelo fato de focalizar as situações de restrição dos direitos, ou de negação deles, como a miséria, a servidão, a mutilação espiritual" (Ibidem, p. 256).

Por meio dessas duas perspectivas, Candido aproxima o direito à literatura aos direitos humanos. $\mathrm{E}$ desses dois direitos ninguém pode ser privado.

Para Castrillón (2011), em $O$ direito de ler, ${ }^{7}$ a leitura, também, ao longo da história, vem se constituindo como uma maneira de dominação dos desvalidos, excluindo-os socialmente. Historicamente, o poder da leitura passou por vários representantes sociais:

[...] primeiro nas mãos da Igreja, que garantia para si, por meio do controle dos textos sagrados, o controle da palavra divina; em seguida, pelos governos aristocráticos $\mathrm{e}$ pelos poderes políticos e, atualmente, por interesses econômicos que dela tentam se beneficiar (CASTRILLÓN, 2011, p. 16).

Também por considerar a leitura como um direito inalienável, com vistas à constituição de uma perspectiva democrática do ato de ler, e não exclusivamente como uma garantia concedida a um segmento social privilegiado, Castrillón esclarece que o contato permanente com a leitura

Não é um luxo das elites que possa ser associado ao prazer e à recreação, tampouco uma obrigação imposta pela escola. É um direito de todos que, além disso, permite um exercício pleno da democracia (CASTRILLÓN, 2011, p. 19). 
Para essa autora, então, a convicção de que "ler pode ser um meio para melhorar as condições de vida e as possibilidades de ser, de estar e de atuar no mundo" (CASTRILLÓN, 2011, p.20) estão diretamente atreladas à imprescindibilidade de fomentar ações e estratégias que assegurem a globalização da cultura letrada. E uma das ações nevrálgicas para Castrillón incide veementemente no investimento necessário e urgente à formação do corpo docente responsável pela formação de leitores:

O propósito de formar leitores exige professores bem formados, conscientes da necessidade de mudanças importantes na estrutura social da escola e atualizados, não por meio de cursos breves ou oficinas, mas sim por meio de programas de longa duração, que partam de sua prática cotidiana e que também introduzam conhecimento da teoria e a necessidade da reflexão e do debate. Formação que lhes permita romper com a tradição de ensinar como aprenderam. Professores também formados como leitores, condição primordial para ensinar a ler e a escrever (CASTRILLÓN, 2011, p. 24).

Essa reflexão de Castrillón traz à tona, pelo menos, três questões fundamentais para o debate em torno dos problemas relacionados à leitura e à formação de leitores. Primeiramente, a velha e batida tecla acerca da necessidade de investimento robusto na formação de professores, pois, sem a mudança desse mofado paradigma, pouco se avançará, como pouco (ou quase nada) se avançou, se considerarmos os dados, aqui, discutidos a respeito dos levantamentos realizados pelo PISA-2018 e pelo RLB-2019 acerca da leitura no Brasil, na árdua empresa de formar leitores autônomos, conscientes e críticos em nosso país. A respeito dessa urgente mudança de arquétipo do professor defasado ou mal formado, Silva (2009), em “O professor leitor", apresenta um argumento contundente:

No Brasil, a formação aligeirada - ou de meia tigela - dos professores, 0 aviltamento das suas condições de trabalho, o minguado salário e as políticas educacionais caolhas fazem com que os sujeitos do ensino exerçam a profissão sem serem leitores. Ou, então, sejam tão somente leitores pela metade, pseudoleitores, leitores nas horas vagas, leitores mancos, leitores de cabresto e outras coisas assim. $O$ resultado desse quadro lamentável e vergonhoso todos sabem: dependência de livros didáticos e outras receitas prontas, desatualização, redundância dos programas de ensino, homogeneização de condutas didáticas, repertório restrito, ausência de habilidades e competências de leitura, estagnação intelectual etc. (SILVA, 2009 , p. 23).

Sequencialmente, a autora tenta desatar o nó górdio da formação docente, ou seja, as sedimentadas práticas e escolhas metodológicas de repetir modelos engessados e empoeirados de se trabalhar com a leitura, ou seja, a adoção dos mesmos recursos para ensinar como se aprendeu sem qualquer questionamento ou distanciamento crítico a respeito da maneira como foi ensinado - seja na educação básica, seja no ensino superior - e como se aprendeu. A respeito dessa apropriação de modelos de ensino ultrapassados, Todorov (2020) questiona o ensino de litera- 
tura na escola, o que pode, perfeitamente, ser estendido ao ensino de leitura: "Como aconteceu de o ensino de literatura na escola ter-se tornado o que é atualmente?" (TODOROV, 2020, p. 35). Em seguida à pergunta, $o$ autor a responde:

Pode-se, inicialmente, dar a essa questão uma resposta simples: trata-se do reflexo de uma mutação ocorrida no ensino superior. Se os professores de literatura, em sua grande maioria, adotaram essa nova ótica na escola, é porque os estudos literários evoluíram da mesma maneira na universidade: antes de serem professores, eles foram estudantes (TODOROV, 2020, p. 35).

Ao assumirmos essa sentença de Todorov como verdadeira, é importante considerarmos a necessidade premente de haver uma reestruturação nos currículos de muitos cursos de licenciatura em Letras, por parte de quem ainda não o fez, propondo novas maneiras de abordagem de leitura e de ensino de literatura, ressignificando as anacrônicas possibilidades de trabalho com a leitura: visão unilateral do que é lido, interpretação do que é lido apoiado exclusivamente na fortuna crítica e leitura de fragmentos textuais em detrimento da leitura integral do texto. Essas são estratégias de leitura e de ensino de literatura ainda muito presentes, tanto na educação básica quanto no ensino superior. É muito importante, então, que tais estratégias com vistas à formação do leitor sejam ressignificadas.

Em se tratando do ensino médio, especificamente, as escolhas das obras a serem lidas contempla quase que exclusivamente autores legitimados pela crítica literária e o ensino de literatura, infelizmente, ainda é bastante calcado na dissecação do texto literário e nas estratégias metodológicas direcionadas aos famigerados exames que selecionam os candidatos ao ingresso no ensino superior. Especificamente a respeito dessa característica do ensino de literatura, identificamos a perpetuação de uma abordagem utilitarista da literatura, cujas práticas leitoras, centradas no ato de esmiuçar do texto literário, estão direcionadas à garantia do sucesso nas avaliações desses exames seletivos. No que diz respeito à análise pormenorizada do texto literário, Bajour (2012), em Ouvir nas entrelinhas: o valor da escuta nas práticas de leitura, ${ }^{8}$ ao refletir acerca da importância de o mediador de leitura ouvir as vozes de seus interlocutores, sinaliza que:

A leitura de um poema, por exemplo, se for apenas uma via para detectar, isolar, dissecar e mencionar hipérboles, sinestesias, antíteses, metonímias etc., deixa de fora a poesia e os leitores.

[...] A teoria é mobilizada a partir daquilo que os leitores dizem sobre os textos, e não de antemão: quando ela precede a leitura, condiciona e fecha sentidos (BAJOUR, 2012, p. 40-41).

Paulino e Cosson (2009), em "Letramento literário: para viver a literatura dentro e fora da escola", estão em franco diálogo com Castrillón, com Todorov e com Bajour quando explicitam que: 
A escola enfatiza demasiadamente o conhecido e o mensurável, negando espaço para o estranho e o inusitado. É o que se observa, por exemplo, no modelo de bom aluno repetidor, cuja competência mais valorizada é dizer aquilo que o livro didático ou o professor já disse: quanto mais literal a repetição, melhor. Também se faz presente na busca dependente que o professor faz de perguntas e respostas prontas nos livros didáticos (PAULINO; COSSON, 2009, p. 71).

Às ideias de Paulino e de Cosson acrescentamos, também, o savoir-faire de muitos estudantes que, conhecedores dos discursos e das ideologias que são caras a muitos professores, sobretudo nos aspectos pertinentes às questões sociais, nas discussões e nos debates, manifestam opiniões em sintonia com o pensamento dos docentes porque são sabedores de que, ao agirem dessa maneira, conquistarão a simpatia e, consequentemente, a aprovação de suas alocuções que estão em total acordo ao pensamento de seus professores. Dito de outra maneira, muitos estudantes valem-se da expertise que possuem para dizer exatamente o que sabem que os professores gostariam de ouvir. Tudo isso, na mesma medida, vale para a produção escrita que os estudantes realizam e que, posteriormente, será lida, muitas vezes, tão somente pelos docentes que solicitaram a produção de textos.

Por fim, a chaga aberta sobre a qual Castrillón espeta o alfinete incide diretamente sobre a importância de que os leitores em formação reconheçam que seus formadores sejam ávidos e contumazes leitores. Sobre esse aspecto, acreditamos ser muito importante que, para fomentarmos práticas de leitura, nossos alunos precisam reconhecer que somos contumazes leitores e que a leitura está organicamente inserida em nossa rotina, quer seja pessoal, quer seja profissional. Para o caso da experiência de leitura, não podemos desconsiderar o fato de que as famílias têm papel preponderante na constituição do sujeito-leitor. Afinal, a criança também aprende pelo exemplo, não somente pela palavra. Por isso, nada adianta os pais falarem para seus filhos lerem se seus filhos nunca os viram/ veem com livros nas mãos. Nesse sentido, crianças que conviveram com pais e avós leitores, por exemplo, têm mais chances de se tornarem igualmente leitoras. Ademais, não podemos nos esquecer de que, para a educação básica desempenhar satisfatoriamente a árdua tarefa de formar leitores, todo o corpo docente deve ser leitor e deve fomentar práticas leitoras junto aos seus discentes. Por isso, a totalidade (ou a maioria) da esfera educacional deve se identificar com a leitura, incorporando-a naturalmente ao planejamento docente. A respeito desse posicionamento, Taufer (2019), em "Prática de escrita criativa na educação básica como alternativa aos processos engessados de produção textual no ensino médio: empoderamento do estudante com vistas à educação literária”, destaca que: 
Todo profissional inserido no campo docente, independente de sua especialidade, jamais deve retirar da sua linha de horizonte de intensões que os atos de leitura (...) são atribuições de toda a escola. Tais atos, de outro modo, constituem-se como conditio sine qua non à adequada formação do estudante e ao seu pleno exercício da cidadania (TAUFER, 2019, p. 124-125, grifo do autor).

Ao encontro do argumento de Taufer, Silva (2009), assevera ser a leitura:

O cerne do desenvolvimento da identidade de um professor é, sem dúvida, a leitura. Para ele, a leitura constitui, além de instrumento e/ou prática, uma "forma de ser e de existir". Isto porque o seu compromisso fundamental, conforme a expectativa da sociedade, se volta para a (re)produção do conhecimento e para a preparação educacional das novas gerações. Professor, sujeito que lê, e leitura, conduta profissional, são termos indicotomizáveis - um nó que não se pode nem se deve desatar (SILVA, 2009, p.23).

Em face do exposto nesta seção, não restam dúvidas a respeito da principal característica que um formador de leitores necessita ter: ser um sujeito permanentemente apaixonado pela leitura e pelos livros, sejam eles físicos, sejam eles virtuais. No entendimento de Santos (2009), em "Agentes de leitura: inclusão social e cidadania cultural", é como se o mediador de leitura dissesse:

[...] "que livro lindo, preciso compartilhar essa beleza com outras pessoas”. Aí pode ser uma criança, um homem, uma senhora que fazem parte de seu itinerário por entre casas, escolas, bibliotecas, hospitais, presídios, pontos de leitura e outros ambientes favoráveis para a leitura (SANTOS, 2009, p. 43).
Além dessa paixão que não pode se esgotar, quem tem a pretensão de trabalhar com o estímulo à leitura deve ter vontade de compartilhar suas experiências leitoras e de ouvir as experiências leitoras de outrem. E essa atitude não deve se restringir ao espaço escolar, mas deve se estender a todos os ambientes em que a leitura seja um valor e em que às práticas leitoras sejam atribuídas a importância inconteste que lhe é devida. Estamos nos referindo aqui, portanto, como já postulou Candido (1995), ao caráter inalienável e ao valor inconteste da literatura, da leitura.

\section{A prática da escuta no compartilhamento das impressões de leitura}

Montag olhou para a parede atrás dos homens, com as listas datilografadas de um milhão de livros proibidos.

Seus nomes saltavam no fogo, reduzindo a cinzas os anos sob seu machado e sua mangueira que não lançava água, mas querosene. (BRADBURY, 2012, p. 54).

Partindo do último ponto discutido na seção anterior, para o mediador de leitura, além de ser um eterno apaixonado pelos livros, na condição de leitor contumaz que deseja fazer com que novos leitores experimentem o antídoto contra a ignorância, a leitura, é preciso a ele 
[...] demonstrar entusiasmo pelo que está lendo, desejo de compartilhar essas experiências com quem convive, apresentando-lhes textos de variadas naturezas, despertando-lhes o interesse pelo manuseio de publicações com recursos desde os mais simples até os mais sofisticados. (SANTOS; NETO; RÖSING, 2009, p. 13).

Bajour (2012), ao discorrer sobre a necessidade de os mediadores de leitura exercitarem a prática da escuta tão necessária ao profícuo trabalho de leitura direcionado à formação de leitores, defende a ideia de que

[...] a tradição escolar, em seu ímpeto tarefeiro, não costuma colocar em primeiro plano o compartilhamento pleno das leituras realizadas pelos alunos, seja entre eles mesmos, seja com o mestre (BAJOUR, 2012, p. 10).

De acordo com as ideias defendidas por essa autora, para os mediadores entre os leitores e o textos é importante pensar a leitura como uma troca de experiências, como um "momento de bate-papo sobre o lido, o intercâmbio acerca dos sentidos que um texto desencadeia em nós” (BAJOUR, 2012, p. 23).

As ideias de Bajour contrapõem-se ao que descrevemos na seção anterior, quando discutimos a respeito das maneiras engessadas e empoeiradas do trabalho ainda realizado com a leitura em muitas instituições de ensino básico e de ensino superior. Segundo os argumentos dessa autora, as abordagens em torno da leitura e do ensino de literatura devem estar dissociadas da nociva dissecação do texto literário, quando a visão a respeito do que foi lido está apoiada apenas na interpretação do professor, o qual, muitas vezes, se apoia sobre os alicerces descontextualizados a fortuna crítica. Não estamos aqui, de maneira alguma, desconsiderando a importância da fortuna crítica a respeito dos textos e dos autores. Questionamos, entretanto, sua validade como única possibilidade de compreensão do texto literário, uma vez esse tipo de visão exclui as impressões dos leitores acerca do lido, desconsiderando a experiência com o texto literário no âmbito da significação personalizada desse texto para cada leitor. Para Bajour, quando o mediador de leitura cede espaço à manifestação das múltiplas vozes de sua comunidade leitora, ele possibilita que os leitores se surpreendam com "os sons de sua própria interpretação. Pôr para fora, para outros, a música de nossa leitura pode nos revelar os realces que conferimos àquilo que lemos, as melodias que evocamos ou a percepção de sua ausência, os ruídos ou os silêncios que os textos nos despertam" (BAJOUR, 2012, p. 23). Para que essa prática da escuta da voz do outro, segundo Bajour, seja convertida em realidade, é importante que o mediador de leitura tenha absoluta clareza de que: 
Escutar, assim como ler, tem que ver, porém, com a vontade e com a disposição para aceitar a apreciar a palavra dos outros em toda sua complexidade, isto é, não só aquilo que esperamos, que nos tranquiliza ou coincide com nossos sentidos, mas também o que diverge de nossas interpretações ou visões de mundo. (...) A democracia da palavra compartilhada implica, (...), o encontro intersubjetivo de vontades que aceitem o outro em sua diferença e estejam dispostas a enriquecer a vida, a leitura e a própria visão de mundo com essa diferença, mesmo que não concorde com ela (BAJOUR, 2012, p. 25).

Na perspectiva de Bajour, os mediadores de leitura, tocados pelo aprendizado da escuta da voz alheia nas discussões e nos debates sobre o compartilhamento das impressões de leitura devem estimular a manifestação da diversidade de possibilidades interpretativas que $o$ texto suscita. O mediador, então, deve, além de contemplar essa multiplicidade de vozes, colocar microfones plugados a caixas de som que amplifiquem as vozes de seus leitores, oportunizando que essas vozes reverberem dentro e fora do espaço de discussão de leituras; enfim, que essas vozes ecoem e se propagem o mais longe possível. Para Bajour, em última análise:

Em experiências de leitura compartilhada, os mediadores que aprendem a ouvir nas entrelinhas constroem pontes e acreditam que as vozes, os gestos e os silêncios dos leitores merecem ser escutados. Se assim for, quando é assim, ler se parece com escutar (BAJOUR, 2012, p. 45).

Para o exercício da leitura compartilhada, tomamos emprestada a expressão communautés interprétavives de Fish
(2007), em Quand lire c'est faire. L'autorité des communautés interprétatives, que, traduzida para a língua portuguesa equivale a "comunidades interpretativas". Em um espaço de compartilhamento de impressões de leitura, todos - mediadores e mediados, professores e alunos - devem "renunciar à imposição de um sentido convencionado, imutável, a ser transmitido" (ROUXEL, 2013, p. 20). Com a principal finalidade de garantir o espaço necessário à manifestação das vozes de todos os participantes de uma comunidade interpretativa, é vital que as discussões e que os debates a respeito do que foi lido partam da recepção do aluno, convidando-o "à aventura interpretativa com seus riscos, reforçando suas competências pela aquisição de saberes e técnicas" (Ibidem, p. 20). E essa aventura interpretativa precisa ser encorajada pelo mediador, que deve estimular os membros de sua comunidade leitora a exteriorizarem seus próprios pensamentos e suas próprias impressões a respeito do que leram. A função reguladora da sala de aula deve ser abolida, e o mediador precisa ter a clareza de que:

A presença da turma é essencial na formação dos jovens leitores: lugar de debate interpretativo (metamorfose do conflito de interpretação), ela ilumina a polissemia dos textos literários e a diversidade dos investimentos subjetivos que autoriza (ROUXEL, 2013, p. 23). 
Em vez de regular a manifestação das impressões de leitura, o mediador precisar ter ouvidos generosos para escutar as experiências de leitura invocadas pelos leitores com quem compartilha vivências e emoções de leitura. A fim de que esse compartilhamento seja eficaz, de acordo com Rouxel (2013), a leitura e a literatura dentro de uma comunidade interpretativa devem proporcionar aos seus integrantes o descobrimento da experiência humana; deve estimular a retirada de proveitos simbólicos personalizados que o mediador não consegue mensurar/avaliar, uma vez que tais proveitos estão restritos ao âmbito individual, portanto íntimo e pessoal. Quando isso tudo ocorre, é bastante provável que igualmente ocorra

[...] enriquecimento do imaginário, enriquecimento da sensibilidade por meio da experiência fictícia, construção de um pensamento, todos esses elementos que participam da transformação identitária (...) (ROUXEL, 2013, p. 24).

Na educação básica, etapa da formação intelectual em que os jovens leitores começam a dar os primeiros passos, a leitura não pode e não deve mais ser apenas uma atribuição dos professores de Língua Portuguesa (ensino fundamental) e Língua Portuguesa e Literatura (ensino médio). A premissa de Guedes e Souza (2011), para cujos autores "Leitura e escrita são tarefas da escola e não do professor de português", é válida porque:
A tarefa de ensinar a ler e a escrever um texto de história é do professor de história e não do professor de português. A tarefa de ensinar a ler e a escrever um texto de ciências é do professor de ciências e não do professor de português. A tarefa de ensinar a ler e a escrever um texto de matemática é do professor de matemática e não do professor de português. A tarefa de ensinar a ler e a escrever um texto de geografia é do professor de geografia e não do professor de português. A tarefa de ensinar a ler e a escrever um texto de educação física é do professor de educação física e não do professor de português. A tarefa do professor de português é ensinar a ler a literatura brasileira (GUEDES; SOUZA, 2011, p. 19).

Considerando o argumento de Guedes e Souza, seria ideal que todos os professores pudessem, também, atuar na condição de mediadores de leitura, destinando alguns minutos semanais de suas aulas para compartilharem informações e impressões de leitura com seus estudantes. E se os professores lessem alguns títulos sugeridos pelos estudantes para compartilharem suas impressões de leitura? Com alguma segurança, podemos afirmar que tais iniciativas corroborariam para tornarem os estudantes participantes ativos das ações de leitura dentro da escola; já os professores ficariam menos assoberbados e menos autoritários a respeito das propostas de leitura, mais maleáveis, portanto, às conversas sobre o ato de ler, saindo da cristalizada figura do "eu" (professores) para a constituição de um "nós" (estudantes e professores). Cabe aos professores que desejam atuar como 
mediadores de leitura, professorarem menos e abrirem mais espaço para as manifestações das vozes sufocadas há séculos, muitas vezes, pela perpetuação de um trabalho com a leitura tradicional demais e exacerbadamente egoísta.

De velhas e falidas práticas de leitura (ainda muito em voga em muitas instituições) nosso sistema de ensino já está enfastiado. Prova desse enfaro são as lancinantes estatísticas do PISA e do RLB apresentadas neste artigo. Ressignificar as práticas leitoras, tanto na educação básica quanto no ensino superior, é uma realidade da qual não podemos fugir, sob pena de ficarmos como estamos: estagnados. $\mathrm{Ou}$, pior, descermos ainda mais degraus na caminhada que deve ser incessante e vigilante rumo à elevação do Brasil à categoria de uma nação que lê muito com propósitos claros de formar leitores emancipados intelectualmente, capazes de formar as próprias opiniões, decisores de seus destinos e espiritualmente elevados, como opina Zilberman (2009).

Resta-nos saber se quem está na vanguarda do nosso sistema educacional, está disposto a mudar a velha maneira de abordar as práticas de leitura que ainda encabeçam boa parte dos locais em que há leitores em formação. Sabemos, todavia, que esse não é um esforço apenas dos docentes para quem a leitura é cara. Como descrevemos na seção introdutória deste artigo, é necessário que as autoridades governamentais estejam igualmente dispostas a ressignificar o espaço escolar, pois o sistema educacional brasileiro, em boa medida, não deve mais ser depositário de docentes: (a) com carga horária elevada, trabalhando em salas de aula superlotadas e atuando em várias escolas para obterem salários um pouco melhores; (b) com planejamentos rígidos, muitas vezes, impostos por quem desconhece a realidade de cada instituição de ensino; (c) com a obrigatoriedade de adotarem o planejamento em série contido nos livros didáticos, os quais não contemplam as especificidades de cada realidade escolar; (d) com o ofício do trabalho com a leitura realizado aos "trancos e barrancos" por quem sequer é leitor; e (e) com a tarefa exclusiva de escolher e de determinar o que os estudantes lerão e, posteriormente, apresentar-lhes uma interpretação unilateral para o que foi lido.

Se nosso sistema educacional continuar eternizando a situação acima descrita, afastará ainda mais os possíveis leitores da leitura; promoverá, metaforicamente, a perseguição e a queima de livros realizada pelos bombeiros do enredo de Fahrenheit $451,{ }^{9}$ de Bradbury (1953). Quem realizará essa queima de livros simbólica, entretanto, serão os jovens que não têm a oportunidade de compartilharem suas experiências de leitura dentro de uma comunidade leitora, negando-se a lerem ou encontrando alternativas para burlarem as propostas 
de leitura que os desagradam porque são escolhas exclusivas do professor.

Por fim, ao contrário de governos intransigentes - que promoveram a queima real de livros porque, juntamente com as obras ateadas ao fogo, incineraram o conhecimento, os ideais - quem se ocupa de impulsionar a formação de leitores, tem o desejo, ainda que utópico, de formar cidadãos com horizontes expandidos, com repertório cultural diverso e extenso, com capacidade crítica para ler os mais distintos contextos em que está inserido. Quem se ocupa de formar leitores não quer, em hipótese alguma, assistir de braços cruzados a ascensão do Império da Ignorância, cujos valores defendidos, em larga escala, são estes:

- A escolaridade é abreviada, a disciplina relaxada, as filosofias, as histórias e as línguas são abolidas, gramática e ortografia pouco a pouco negligenciadas, e, por fim, quase totalmente ignoradas. A vida é imediata, o emprego é o que conta, o prazer está por toda a parte depois do trabalho. Por que aprender alguma coisa além de apertar botões, acionar interruptores, ajustar parafusos e porcas? (BRADBURY, 2012, p. 78).

Quem se ocupa da árdua tarefa de lutar contra o status quo vigente no que diz respeito às práticas leitoras, há muito ultrapassadas, tenciona uma sociedade muito diversa da que foi descrita por Bradbury (2012) em Fahrenheit 451. Certamente, haverá inúmeros percalços no meio do caminho, mas em meio ao asfalto escaldante será possível vislumbrar a flor, aqui bela, que "Furou o asfalto, o tédio, o nojo e o ódio" (DRUMMOND, 2015, p. 107) e vingou.

\section{Considerações finais}

Depois da explanação que fizemos a respeito de algumas estatísticas que mensuram os nossos níveis de leitura, considerando o levantamento realizado pelo PISA e pelo RLB, cujas análises dos dados gerados revelaram estar o Brasil dentro de uma categoria muito aquém da esperada, isto é, a de um país que pouco prioriza a leitura e que parcamente reconhece o trabalho dos profissionais que lutam para que a leitura seja um direito de todos, encerramos esta discussão apontando algumas falhas nas práticas leitoras que perpetuam modelos ainda muito reproduzidos em muitas instituições educacionais. Entretanto, nosso propósito esteve bem distante de apenar a nosso sistema de ensino; pelo contrário, apresentamos alternativas possíveis, como a criação de comunidades interpretativas, para assegurar a diversidade de vozes ao se debater um texto literário, por exemplo. Se tivermos o claro entendimento de que a educação básica ainda é o local beneficiado para formar leitores, será mais fácil nos arriscarmos aos experimentos que a leitura suscita, será mais fácil estimular os leitores a mergulharem no universo aventureiro proporcionado pelo livros. 
Hoje, de maneira muito diversa à época em Castro Alves (1847-1871) viveu, temos uma superabundância de obras e de autores que não havia no Século XIX, fato que facilita (e muito) o acesso à leitura, considerando, também, os meios virtuais disponíveis para o contato frequente com os livros, como o audiolivro, entre outros. Quando o autor do poema O Livro e a América bradou Oh! bendito o que semeia / Livros... livros à mão cheia... / E manda o povo pensar!, intuitivamente, preconizou o insubstituível ofício do bendito semeador de livros - o mediador de leitura - que, com estratégias leitoras eficazes, fomenta o amor e o apreço aos livros, fontes inesgotáveis de aprendizado e de onde o conhecimento extraído manda o povo pensar, libertando-o dos grilhões seculares do aprisionamento intelectual.

\section{Some aspects of reading in Brazil: old behaviors, possible alternatives}

\section{Abstract}

the present paper is based on an analysis of some data from the latest results of Programa de Avaliação Internacional dos Alunos (PISA) and of Retratos da Leitura no Brasil (RLB), the first made available by INEP, the second by Instituto Pró-Livro, in which low reading rates are discussed in a perspective that questions the profile of the national reader and the misconceptions related to the course of their education when trying to delineate it from the school space, precisely because this space is fragile, far from investments by several natures that, in fact, guarantee to visualize the profile of which he is so sorry. The aim is not to reveal a reality already known to embarrass teachers and students, but to resume it, since the indexes, in our view, point once again to it, and put it in dialogue with the studies of José Hélder Pinheiro Alves (2013), Antonio Candido (1995), Silvia Castrillón (2011), Graça Paulino e Rildo Cosson (2009), Tzvetan Todorov (2020), Regina Zilberman (2009), among others, to suggest some reflections. In the end, we present possible alternatives in the context of Brazilian basic education, such as the creation of interpretive communities, taking advantage of Annie Rouxel's (2013) guidelines, in line with what Cecilia Bajour (2012) proposes about listening as a reading practice, methodologies that, if well observed, will recover aspects that are in the nature of the reception of the literary text, which is already a suggestion.

Keywords: Literary reading; Literature at school; Reading practices.

\section{Notas}

1 Programme for International Student Assessment (PISA) consiste no relatório de informações sobre o desempenho dos estudantes de 15 anos de idade. No Brasil, o PISA é realizado a cada três anos pela Organização para a Cooperação e Desenvolvimento Econômico (OCDE). No documento, são disponibilizados dados relativos ao desempenho dos estudantes nos aspectos concernentes à aprendizagem intra e extraescolar. A interpretação dos dados gerados possibilita aos países: (a) avaliarem conhecimentos dos estudantes, contrastando com os dados obtidos nos demais países; (b) instrumentalizarem-se com políticas e 
práticas exercidas em outros lugares; e (c) elaborarem, a partir de comparações feitas, programas educacionais próprios com objetivos claros para qualificar a aprendizagem dos estudantes. O documento completo está disponível em: https:// download.inep.gov.br/publicacoes/institucionais/ avaliacoes_e_exames_da_educacao_basica/relatorio_brasil_no_pisa_2018.pdf

2 Retratos da Leitura no Brasil (RLB) consiste na investigação realizada no perímetro nacional com finalidade de diagnosticar o perfil leitor do brasileiro, avaliando seus hábitos leitores. Os dados gerados direcionam a avaliação de políticas públicas do livro, os estudos e os projetos de leitura em nosso país. A pesquisa do RLB, em todo o território brasileiro, a partir de 2007, passou a ser realizada pelo Instituto Pró-Livro (IPL). Em 2019, o IPL realizou a $5^{\mathrm{a}}$ edição do RLB. O documento completo está disponível em: https://prolivro.org. br/wp-content/uploads/2020/09/5a_edicao_Retratos_da_Leitura_no_Brasil_IPL-compactado.pdf

3 Monteiro Lobato, figura central no desenvolvimento da indústria editorial brasileira, em 1918, quando ainda dava os primeiros passos rumo ao mercado editorial, fez veementes críticas ao governo devido às baixas tarifas atribuídas aos livros importados. Obviamente, as obras estrangeiras, mais baratas, competiam em vantagem sobre os livros nacionais. Além disso, os livros provenientes de Portugal eram isentos de impostos. Na condição de editor, Lobato defendia, portanto, a taxação das obras estrangeiras, pois, naturalmente, vislumbrava benefícios para suas obras que eram nacionais.

5 Temos clareza sobre a divergência de posicionamentos que circundam a expressão "ensino de literatura”. Também acreditamos que não se ensina literatura, mas, considerando as diferentes vivências e o repertório de leituras de quem trabalha com a literatura, cremos que aspectos sobre a literatura possam, sim, ser ensinados.

5 Constitui-se como a principal avaliação internacional em educação, aferindo, de três em três anos, o desempenho de estudantes com idades entre 15 e 16 anos, quando a maioria desses jovens está se encaminhando para a conclusão da educação básica. Participam dessa avaliação 79 países ou regiões que são integrantes ou parceiros da OCDE. O Brasil está entre essas nações. É importante esclarecer que esse teste, com duração máxima de duas horas, é realizado via computador. Ademais, tal aferição mede as competências de leitura, de matemática e de ciências dos estudantes submetidos ao teste do PISA.
6 Para a concretização dessa pesquisa, 8.076 entrevistas foram realizadas em 208 municípios. Os dados foram colhidos entre outubro de 2019 e janeiro de 2020.

7 Conferência proferida na Feira Internacional do Livro de Bogotá, em 2003, no Primeiro Colóquio Colombiano-Francês de Bibliotecas Públicas "Biblioteca y Sociedad".

8 Comunicação apresentada em Bogotá, em 2008, na 5 a Jornada de Reflexão sobre a Leitura e a Escrita, evento organizado pela Secretaria de Educação de Bogotá e pela Associação Colombiana de Leitura e Escrita (Asolectura).

9 O título da obra faz referência à temperatura de combustão do papel do livro.

\section{Referências}

ALVES, Castro. Obra completa. Rio de Janeiro: Nova Aguilar, 1986.

ALVES, José Helder Pinheiro. O que ler? Por que ler? A literatura e seu ensino. In: DALVI, Maria Amélia; REZENDE, Neide Luzia de; JOVER-FALEIROS, Rita. (Orgs.). Leitura de literatura na escola. São Paulo: Parábola, 2013, p. 35-49.

ANDRADE, Carlos Drummond de. Nova reunião: 23 livros de poesia. São Paulo: Companhia das Letras, 2015.

BAJOUR, Cecília. Ouvir na estrelinhas: o valor da escuta nas práticas de leitura. Tradução: Alexandre Morales. São Paulo: Pulo do Gato, 2012.

BRADBURY, Ray. Fahrenheit 451. Tradução: Cid Knipel. São Paulo: Globo, 2012.

CANDIDO, Antonio. O direito à literatura. In: CANDIDO, Antonio. Vários escritos. $3^{\text {a }}$ ed. rev. e ampl. - São Paulo: Duas Cidades, 1995, p. 235-263.

CASTRILLÓN, Silvia. O direito de ler e de escrever. Tradução: Marcos Bagno. São Paulo: Pulo do Gato, 2011.

FISH, Stanley. Quand lire c'est faire. L'autorité des communautés interprétatives. Paris: Les Prairies ordinaires, 2007. 
GUEDES, Paulo Coimbra; SOUZA, Jane Mari de. Leitura e escrita são tarefas da escola e não do professor de português. In: NEVES, Iara Conceição Bittencourt et al. (Orgs.). Ler e escrever: compromisso de todas as áreas. 9. ed. Porto Alegre: Editora da UFRGS, 2011.

INEP. Programa de Avaliação Internacional dos Alunos (PISA). Disponível em: https://download.inep.gov.br/publicacoes/ institucionais/avaliacoes_e_exames_da_educacao_basica/relatorio_brasil_no_pisa_2018. pdf. Acesso em: 28/12/2020.

INSTITUTO PRÓ-LIVRO. Retratos da Leitura no Brasil. São Paulo: Instituto Pró-Livro, 2018. Disponível em: https://prolivro. org.br/wp-content/uploads/2020/09/5a_edicao_Retratos_da_Leitura_no_Brasil_IPL-compactado.pdf. Acesso em: 28/12/2020.

PAULINO, Graça; COSSON, Rildon. Letramento literário: para viver a literatura dentro e fora da escola. In: ZILBERMAN, Regina. RÖSING, Tânia Mariza Kuchenbecker. (Orgs.). Escola e leitura: velha crise, novas alternativas. São Paulo: Global, 2009, p. 61-79.

ROUXEL, Annie. Aspectos metodológicos do ensino da literatura. Tradução: Neide Luzia de Rezende. In: DALVI, Maria Amélia; REZENDE, Neide Luzia de; JOVER-FALEIROS, Rita. (Orgs.). Leitura de literatura na escola. São Paulo: Parábola, 2013, p. 17-33.

SANTOS. Fabiano dos. Agentes de leitura: inclusão social e cidadania cultural. In: SANTOS, Fabiano dos. et al. (Orgs.). Mediação de leitura: discussão e alternativas para formação de leitores. São Paulo: Global, 2009. p. 37-45.

SILVA, Ezequiel Theodoro da. O professor leitor. In: SANTOS, Fabiano dos. et al. (Orgs.). Mediação de leitura: discussão e alternativas para formação de leitores. São Paulo: Global, 2009. p. 26-36.
TAUFER, Adauto Locatelli. Prática de escrita criativa na educação básica como alternativa aos processos engessados de produção textual no ensino médio: empoderamento do estudante com vistas à educação literária. In: TAUFER, Adauto Locatelli. et al. Escrita criativa e ensino I: diferentes perspectivas teórico-metodológicas e seus impactos na educação literária. Coleção Educação, volume 5. Jundiaí: Paco Editorial, 2019, p. 123-146.

TODOROV, Tzvetan. A literatura em perigo. Tradução: Caio Meira. $10^{\mathrm{a}}$ ed. Rio de Janeiro: Difel, 2020.

ZILBERMAN, Regina. A escola e a leitura da literatura. In.: ZILBERMAN, Regina; RÖSING, Tânia Mariza Kuchenbecker. (Orgs.). Escola e leitura: velha crise, novas alternativas. São Paulo: Global, 2009, p. 17-39. 